\title{
SANEAMENTO NAS ESCOLAS PÚBLICAS
}

\author{
Maria de Lourdes Locato* \\ João Elias Toscani Cabrera ** \\ Margarida Bandeira S. Melo***
}

\begin{tabular}{l|l|}
\cline { 2 - 2 } & $\mathrm{RBEn} / 08$ \\
\hline
\end{tabular}

LOCATO, M.L., CABRERA, J.E.T. e MELO; M.B.S. - Saneamento nas escolas públicas. Rev. Bras. Enf.; DF, 29 : 64-70, 1976.

\section{INTRODUÇAO:}

A magnitude dos problemas de Educação e Saúde, dentre os quais é significativo o das construçōes escolares nas regiōes subdesenvolvidas ou em processo de desenvolvimento, devido a sua carência e precariedade, tem preocupado educadores e sanitaristas, no plano nacional e internacional.

Em sua maioria, nossas escolas não cessárias à formação de bons hábitos hisárias à formação de bons hábitos higiênicos e à manutenção da saúde dos escolares, principalmente nas zonas suburbanas e rurais.

Objetivos:

- Estabelecer normas gerais de saneamento básico para os locais de ensino-aprendizagem.

- Proporcionar a aquisição de conhecimentos, hábitos e atitudes positivas em relação a saúde.

- Prevenir doenças e acidentes.
- Promover o ajustamento físico, mental e social da população escolar.

Desenvolvimento:

Requisitos Físicos de Saneamento

Escolar:

fonveniente estabelecr critérios referentes às construçōes escolares, tendo em vista as características do terreno, o prédio, o custo das construçōes; sua utilização e manutenção; e boa técnica de engenharia necessária à segurança e à higiene.

Segurança:

O terreno deverá ser uma área firme, afastada de locais ou prédios que desenvolvam atividades anti-socials, perniciosas aos escolares.

Deve-se evitar terrenos acidentados, afim de eliminar problemas de drenagens, nas inundaçōes.

- Enfermeira Supervisora da Secretaria da Saúde - São Paulo, SP.

* Médico da Secretaria de Saúde - Porto Alegre, RS.

** Odontóloga da Secretaria de Saúde - Teresina, PI. 
LOCATO, M.L., CABRERA, J.E.T. e MELO; M.B.8. - Saneamento nas escolas públicas. Rev. Bras, Ent.; DF, $29: 64-70,1976$.

O edifício escolar deverá ser térreo, ou de apenas dois andares, variando a construção de acordo com a área que será servida.

As escadas terão degraus apropriados ao escolar, com espelho de $25 \mathrm{cms}$ e altura de $16 \mathrm{cms}$, ou rampas, cuja inclinação não exceda a $10 \%$, de piso áspero, não escorregadio, lavável e resistente.

A construção atenderá as exigências de proteção em casos de emergência, tais como fogo e enchentes.

As paredes internas não devem ter superficies contundentes e serem pintadas de cores claras.

Se possível evitar construção de madeira, cobertas de palha.

Locais de trânsito; os corredores deverão ter largura acima de 1 metro, dependendo do tamanho da escola.

Nos patamares não deverá haver portas abrindo para fora.

Localização das escolas: longe de cruzamentos e vias perigosas; distantes até $3,5 \mathrm{Km}$ das vias de acesso, na zona urbana; na zona rural em cada $6 \mathrm{~km}$ de estrada deverá haver uma escola.

Ambiente Físico:

\section{- Disposição do Prédio:}

A disposição do prédio obedecerá a determinação da topografia do terreno, condiçōes climáticas e sócio-econômicas das regiōes e proximidade de construçōes vizinhas.

Convém dar maior importância a orientação do prédio em relação ao sol, de modo a evitar sua excessiva incidência no interior da sala de aula, sendo possível, promover o plantio de árvores. Na maioria das regiōes brasileiras as salas de aula estão orientadas entre SE e NE, permitindo melhor lluminação.

A proteção contra ventos fortes deve ser através de quebra-vento, principalmente em áreas rurais onde se utilizam cercas vivas de eucaliptos.
Elementos que constituem o prédio escolar: salas de aula, desde uma ou duas até dezesseis no máximo, cantina com depósito para gêneros alimentícios; depósitos de materiais, conjuntos sanitários para alunos, professores, diretor e outros funcionários; recreio coberto, área livre, corredor de acesso; área coberta para merenda; residência do zelador; sala para orientador, secretaria, biblioteca, sala de artes industriais, gabinete médico-dentário e sala para material de saúde, que constará do necessário para atendimento de emergências.

Salas de aulas: a forma das salas de aulas será de preferência retangular, com a seguinte dimensão: largura de $2 / 3$ ou $4 / 5$ do comprimento, podendo ser ampliada; seu acesso deve ser pelo lado mais ensolarado, protegido por coberturas.

Iluminação e Ventilação: poderão ser obtidas por um conjunto de janelas, cujas somas de suas áreas corresponderão a 1/4 ou 1/5 da área do piso.

As alturas das janelas devem ser de 1/6 do pé direito; devem abrir todas para o mesmo lado e as carteiras deverão ser situadas de tal maneira que o quadro-negro colocado em frente ao aluno, receba luz pela esquerda. Súa pintura se processará com tinta fosca e sua disposição impedirá reflexos de luminosidade.

Volume de ar: está compreendido a um mínimo de $5,0 \mathrm{~cm}^{3}$ e um razoável de $6,5 \mathrm{~cm}^{3}$, o que dá de acordo com o pé direito mínimo de $3,20 \mathrm{~m}$ uma área de piso de $1,50 \mathrm{~m}^{2}$ por aluno.

Instalaçōes elétricas: devem ser constituídas de pontos de luz variando com as necessidades, instaladas por um interruptor duplo e ainda de duas tomadas em paredes opostas.

Mobillário: constituído de cadeira e mesa para professores; armário grande para livros, papéis, cadernos e caixinha de pronto-socorro.

Painéis para fixar avisos, mapas e cartazes. 
LOCATO, M.L., CABRERA, J.E.T. e MELO; M.B.S. - Saneamento nas escolas públicas. Rev. Bras. Enf.; DF, $28: 64-70,1976$.

Cadeiras e mesas dos alunos: devem ser cômodas e práticas, favorecendo uma boa postura dos estudantes e tendo espaços para guardar objetos; não devem ser fixas, permitindo o deslocamento para dramatizações, trabalhos em grupo, projeções e aulas ao ar livre, etc.

A decoração das salas de aulas e de todo o prédio, juntamente com o equipamento escolar, devem tornar a escola alegre e acolhedora.

Grande parte da decoração deve ser confiada ao trabalho dos próprios alunos.

Do ponto de vista da educação é importante que a criança contribua para a conservação e embelezamento da escola.

Recreio: toda escola deve ter um pátio para recreação dos alunos e uma área coberta que deverá ter uma superfície pelo menos igual a metade da soma das áreas das salas de aula; convém localizá-lo em local que não perturbe os trabalhos da administração, mas que permita fácil fiscalização.

Integrados ou próximos dele, deverão ficar o depósito, cantina e sala de merenda.

A área de recreio necessária por aluno é de 5 a $10 \mathrm{~m}^{2}$, a área coberta poderá ser de 1/4 da área de recreio.

Deverá haver também um local para reuniões dos alunos e da comunidade, onde deverá ser previsto um palco para festas cívicas e recreação.

Area para educação física: - é imprescindivel em toda a escola, com instalações para ginásticas e jogos.

Cantina: destina-se ao preparo e distribuição de lanches, leite, sopas, etc. Deverá ter instalados, um fogão, um armário, pia, uma banca de preparo de lanches e um balcão de distribuição para a sala da merenda.

Contará ainda com um depósito para gêneros alimentícios e prateleiras de mármore ou madeira.

Jardim: toda a escola deverá ter plantas e flores, onde se encontra um pouco da natureza, que humaniza o homem.
Horta: havendo área é bom ter uma, cultivada pelos alunos, para que aprendam a comer verduras e legumes que serão usados na merenda para enriquecer a sopa.

Administração: constituída de uma Diretoria, sala dos professores, sala de reuniōes, anfiteatro, gabinete médicodentário, sala para material de saúde (emergências) e biblioteca próximo ao corredor de entrada da escola.

Sala de artes industriais: deverá existir nas escolas que agrupam crianças com idade superior a 7 anos que têm capacidade para trabalhos de artes domésticas, educação para o lar, artes em geral.

Deverá ter algum maquinário de acordo com a matéria que será ministrada e bastante orientação e vigilância para evitar acidentes com os alunos.

Biblioteca: de preferência próxima da administração e de acesso fácil, devendo a sala de leitura ter uma área de $1,8 \mathrm{~m}^{2}$ por leitor.

Seus móveis devem ser simples, resistentes, de fácil limpeza e oferecer conforto aos estudantes.

As estantes deverão ser baixas, as mesas e cadeiras deslocáveis para que os alunos possam fazer leituras em grupos.

$O$ ambiente deve ser estimulante $e$ acolhedor, dando-se importância à decoração.

Gabinete médico-dentário: consta de duas salas conjugadas, dotadas de pias, com suficiente espaço para equipamento odontológico, exames gerais e material de primeiros socorros para atendimento das emergências.

Saneamento básico: baseia-se no abastecimento d'água, destino dos dejetos, lixo, esgoto, controle dos vetores, conservação e manutenção da limpeza nas escolas.

Abastecimento d'água: toda a escola necessita ter sua caixa de água própria, satisfazendo em qualidade e quantidade, com capacidade adequada, na razão de 
LOCATO, M.L., CABRERA, J.E.T. e MHLO; M.B.S. - Saneamento nas escolas públicas. Rev. Bras Enf.; DF, 29 : 64-70, 1976.

30 litros por aluno, inclúda a água necessária à limpeza e irrigação do jardim e horta; esta taxa poderá ser aumentada.

Quando não houver água encanada no local, utiliza-se água de um poço previamente construído, usando-se bomba de sucção.

Em áreas onde existe abastecimento público, deve-se obter ligação direta para a escola.

E conveniente que a água quando não tratada, ou seja, com qualidade insatisfatória, passe por um tratamento em um filtro de areia ou arenito.

Quanto à aparelhagem deve ser o mais próximo possível daquela que $o$ aluno tiver em casa, para não desajustá-lo no seu ambiente familiar. Aliás, todo o conjunto escolar deverá ser aproximadamente igual à área onde vivem os alunos, para não arrancá-lo da sua realidade de maneira drástica.

Lavatórios: também são previstos nas instalaçōes hidráulicas: - pias na saída das privadas e nos locais de recreio.

Bebedouros: na proporção de $1 / 100$ alunos, com jato inclinado, para melhor higiene.

Chuveiros: $1 / 20$ alunos, separados por sexo, 1 para os funcionários.

Destino dos dejetos: as escolas deverão ter grupos sanitários independentes, para alunos, professores e outros funcionários, também que se assemelhem aos de suas casas.

Há necessidade de uma privada para 20 alunos, separada por sexos, situada em locais que ofereçam condiçōes sanitárias satisfatórias.

O mictório deve ser construído na base de $1 / 30$ alunos.

As paredes devem ser revestidas de preferência de azulejos até o teto, ou com tintas plásticas, claras e laváveis.

As portas de acesso ao conjunto sanitário deverão ser colocadas de modo a impedir que se devassem o seu interior.
As janelas serão colocadas no mínimo, 2,0m acima do piso.

Lixo: Cada sala de aula, cada compartimento deverá ter uma cesta para papel usado. Nos locais de recreação e de merenda, serão previstos recipientes metálicos estanques, com fechamento hermético e automático, podendo conter até 250 grs. de resíduos por aluno e por dia.

Remoção do lixo: nas zonas urbanas existe a coleta pública. Nas suburbanas poderá ser queimado, onde não existir coleta.

Nas zonas rurais: o lixo deve ser enterrado, podendo haver a colaboração dos alunos para esta atividade.

Esgoto: tem por objetivo a remoção dos dejetos humanos, ligado à rede de esgotos da localidade, quando existir essa canalização.

O sistema de esgoto pode variar, entretanto ele pode ser: - unitário, quando é destinada uma única rede para a remoção de dejetos, águas domiciliares ou urbanas e pluviais.

Ainda, pode ser canalização separada uma para dejetos e outras para águas domiciliares ou para todas as águas.

Latrinas e mictórios: ligados ao esgoto, em gabinetes sanitários que não se comuniquem com a cozinha, a copa ou o refeitório.

O tipo será de acordo com as possibilidades da região, privada patente, fossa seca, de fermentação, fossa negra, etc.

Controle dos vetores e animais nocivos: tem grande importância sanitária, devido a possibilidade de transmissão de doenças, tais como: peste bubônica, leptospirose, outras doenças bacterianas, shigueloses, salmoneloses, contaminando os alimentos, além do risco de picadas e mordeduras.

O controle visa o extermínio de ratazanas, moscas, baratas, aranhas, escorpiōes, cobras, etc., através de medidas gerais como: proteção dos alimentos, dos reservatórios d’água, remoção do lixo, 
LOCATO, M.L., CABRERA, J.E.T. e MELO; M.B.S. - Saneamento nas escolas públicas. Rev. Bras. Enf.; DF, 2S : 64-70, 1976.

limpeza do ambiente, fechamento de buracos, remoção de objetos inútels, quebrados e fora de uso, das zonas de circulação e permanência dos escolares.

Nas escolas rurais proceder ao desmatamento, afastando os focos o mais possível da escola e protegendo-as contra os animais nocivos.

Limpeza e manutenção da higiene: através de açōes diárias e da educação dos escolares, os locais escolares deverão ser limpos e conservados, afim de que possam servir à prevenção e manutenção da saúde.

Também os reparos e a conservação das instalaçōes sanitárias é de suma importância, devendo ser objeto de atenção da direção da escola, com a colaboração dos alunos, suas famílias e da comunidade servida pela mesma.

Nota:

Até aqui descrevemos tipos de escolas que se aproximam do ideal. Entretanto sabemos que $2 / 3$ das escolas brasileiras são deficientes nas suas instalaçōes de saneamento; existem escolas por todo o pais, principalmente as isoladas, as rurais e as de emergência, funcionando em barracōes de madeira, cobertas de palha (sapê, côco, babaçu) e de chão batido, com bancos toscos ou sem nenhum assento a não ser o próprio piso; sem quadro-negro; com "privada" no mato; sem água ou em latōes de limpeza bastante duvidosa e sem proteção.

Outras, funcionando precariamente em prédios muito velhos, estragados, sem possibilidades de educar, nem de manter a higiene dos escolares.

\section{Aspectos educacionais}

Qualquer programa que venha a ser desenvolvido em Educação Saúde, deverá fazer parte de um plano integral, estreitamente vinculado ao desenvolvimento econômico de cada região, dentro do conceito de educação como investimento.

A educação sanitária compreende uma série de atividades que visam proporcionar à criança e ao jovem, a aquisição de conhecimentos, hábitos $e$ atitudes positivas em relação à saúde.

A criança aos 7 anos, já superou a fase de adaptação familiar e inicia a etapa escolar, que é um período de muita receptividade, para incorporar aos seus esquemas assimiladores, hábitos higiênicos, que levará para a vida futura.

Na moderna reforma do ensino, Saúde entra no núcleo comum do $1 .^{\circ}$ e $2 .^{\circ}$ graus, devendo ser ensinada pelos professores, integrada com outras matérias, numa aprendizagem global.

Devem ser focalizados os seguintes aspectos: controle e prevenção das principais doenças e acidentes; implantação de hábitos sadios; melhor compreensão da personalidade da criança e do jovem; reintegração do aluno desajustado ao ensino e ao grupo familiar; integração lar-escola-comunidade.

\section{Controle e prevenção das principais doenças}

Os escolares podem apresentar: problemas de visão, audição, lentidão na aprendizagem, desajustamentos emocionais e incoordenação motora. Verminoses, desnutrição, doenças infecto-contagiosas, anomalias orgânicas, doenças crônicas, alergías, asma, doenças parasitárias, gastro-enterites, cáries dentárias.

O professor deve estar preparado e vigilante para observar esses desvios da normalidade, procurando orientar e encaminhar os alunos para o setor de saúde ou de orientação psicológica, ajudando-os a vencer essas dificuldades, em colaboração com os pais. Também deve orientar a conduta a seguir nas doenças e também a sua prevenção.

Auxiliar o trabalho da Unidade Sanitária, esclarecendo ös alunos e familiares da importância da imunização, exi- 
LOCATO, M.L., CABRERA, J.E.T. e MELO; M.B.S. - Saneamento 'nas escolas públicas. Rev. Bras. Enf.; DF, 29 : 64-70, 1976.

gindo no ato da matrícula a caderneta da vacinação atualizada.

Colaborar na divulgação das campanhas; incentivar os alunos na confecção de cartazes e na distribuição de volantes; encaminhar os estudante para o Posto de Saúde ou receber os vacinadores na escola.

Prevenção de acidentes: Os escolares estão sujeitos a acidentes variados: quedas, contusōes, cortes hemorrágicos, epistaxe, luxaçōes, fraturas, atropelamentos, desmaios, afogamentos, etc. Nos grandes centros urbanos estão sujeitos também a seqüestros, mortes e a vícios de drogas tóxicas e perversōes sexuais.

Conduta do professor: Além de manter com a colaboração dos alunos, medidas de saneamento nas escolas, deverá solicitar das autoridades competentes os reparos necessário a essas medidas.

Dar orientação clara e contínua desde que haja ou não acidentes, ensinando os alunos a usufruir do meio físico.

Explicar aos seus alunos os perigos no trânsito; nos lugares ermos e distantes; o perigo de acompanharem pessoas estranhas; e o risco que correm aceitando e usando drogas tóxicas, por curiosidade ou imposição de "passadores", prevenílos também para se precaverem com aqueles que os querem iniciar a práticas sexuais nocivas à saúde.

Estar preparado para dar atendimento nas emergências, prestando os primeiros socorros e encaminhando para os locais de tratamento.

Manter em ordem o seu material de pronto-socorro, com a colaboração dos alunos, que devem aprender a usá-lo, com reposição.

Implantação de hábitos sadios

Higiene individual: é na escola que a criança valoriza mais os cuidados de higiene, quando tem ligação afetiva com o professor. Deverá ser orientada na higie- ne das mãos, cabelos, unhas, asseio geral, das roupas e calçados.

Higiene da boca e encamínhamento ao dentista.

Orientada quanto a boa postura e a posição correta para a leitura.

Higiene do ambiente: os escolares precisam ser motivados para colaborar na limpeza de sua escola e de sua casa. Dar destino adequado ao lixo. Usar corretamente o aparelhamento sanitário. Contribuir para a manutenção da limpeza nos locais públicos.

Higiene alimentar: aproveitar da hora da merenda para esclarecr o valor da alimentação adequada; a mastigação correta e a higiene dos alimentos e das mãos e a limpeza dos locais de refeição.

Higiene sexual: partindo de exemplos de plantas e bichinhos ou usando livrostexto especiais o professor deve esclarecer meninos e meninas sobre os cuidados e o desenvolvimento com o seu corpo. Tratar de reprodução humana de maneira natural e oportuna, aproveitando a curiosidade das crianças e a integração com matérias correlacionadas.

Exercícios físicos: jogos, competiçōes, deverão ser incentivados, mas sem exagerar na violência. Promover excursōes e passeios ao ar livre.

Relacionamento professor-aluno: desenvolver a criatividade, iniciação artística e musical; dramatizaçōes; favorecer o lazer, propiciando o bom relacionamento entre os componentes da escola e os estudantes, tendo em vista a socialização da criança e a sua saúde mental.

Procurar a reintegração dos alunos desajustados, em colaboração com a familia.

Integração Lar-Escola-Comunidade: A escola deve se constituir num centro ativo da vida social da comunidade, através dos pais de alunos principalmente nas regiōes suburbanas, cidades de interior e nas zonas rurais, onde isto é possível.

$O$ professor deve ser 0 desencadeador do processo de desenvolvimento junto da 
LOCATO, M.L., CABRERA, J.E.T. e MELO; M.B.S. - Saneamento nas escolas púpúblicas. Bev. Bras, Enf.; DF, 29 : 64-70, 1976.

comunidade, interessando os líderes locais na melhoria da escola.

Campanhas de limpeza e mutirōes poderão ser feitos conjuntamente, para construção de fossas; limpeza e embelezamento da escola e das casas; horta comunitária; criação de pequenos animais.

Campanhas de saúde com escolares sob a responsabilidade da escola, em colaboração com a Unidade Sanitária, podem motivar a comunidade.

Responsabilidades dos profissionais de Saúde Pública

Deverão ministrar cursos de férias para professores sobre educação sanitária nas escolas.

Participar quando se apresentar oportunidade, de reuniōes da Associação de
Pais e Mestres, afim de debater com eles problemas dos escolares: higiênicos, sexuais e desajustamentos no lar e na escola.

Interessar universitários de saúde em programas de Ação Comunitária integrados com a escola, tendo a finalidade de educar para a saúde, o que é um direito e um dever de todos.

Conclusōes

As medidas de saneamento nas escolas, além de proporcionarem condiçōes de melhoria da saúde dos estudantes. professores e outros elementos, ainda trazem vantagens econômicas, propiciando melhor rendimento escolar e contribuindo para o desenvolvimento do país. 